\title{
LISINA PARA FÊMEAS SUÍNAS PRIMÍPARAS EM LACTAÇÃO E O EFEITO NO DESEMPENHO DOS LEITÕES
}

\author{
Carlos Alexandre Oelke ${ }^{1}$, Fabiano Dahlke ${ }^{1}$, Alex Maiorka ${ }^{1}$, Marson Bruck \\ Warpechowski ${ }^{1}$, Ricardo Vianna Nunes ${ }^{2}$, Tiago Junior Pasquetti ${ }^{2}$ \\ 1 Universidade Federal do Paraná - carlosoelke@hotmail.com \\ 2 Universidade Estadual do Oeste do Paraná
}

\begin{abstract}
RESUMO: O objetivo foi avaliar o melhor nível de lisina a ser utilizado na ração de fêmeas suínas de primeiro parto em lactação, em relação ao desempenho dos leitões ao desmame, e também avaliar o número de fetos e peso dos leitões no segundo parto. Foram utilizadas inicialmente 50 porcas primíparas em lactação, distribuídas entre os 5 tratamentos (10 animais por tratamento), sendo que os tratamentos foram os diferentes níveis de lisina digestível na ração, correspondendo a 0,$88 ; 0,99$; 1,$04 ; 1,08$ e $1,24 \%$, mantidas as relações entre os demais aminoácidos. As leitegadas foram padronizadas com 11 leitões. Esses animais foram distribuídos em um delineamento experimental de blocos ao acaso, sendo cada leitegada uma unidade experimental, assim obtendo-se 10 repetições. As variáveis analisadas foram submetidas à análise de variância e regressão. Não houve diferença estatística em relação ao peso dos leitões ao desmame, e tampouco do peso e número de fetos no segundo parto em função dos níveis de lisina. Conclui-se que os diferentes níveis de lisina não influenciam o desempenho dos leitões, podendo assim, ser utilizado o menor nível estudado $(0,88 \%$ de lisina digestível) na dieta de porcas primíparas em lactação.
\end{abstract}

Palavras-chave: aminoácidos digestíveis; leitegada; fetos; porcas lactantes

\section{LYSINE FOR PRIMIPAROUS LACTATING SOWS AND EFFECT IN THE PERFORMANCE OF THE PIGLETS}

\begin{abstract}
The present study aimed to determinate optimum lysine levels to be used in the ration of primiparous sows in lactation, in relation to piglets performance at weaning. Fifty primiparous sows in lactation were used, and distributed among five treatments (10 animals per treatments), and each treatments contained different levels of digestible lysine in the ration, corresponding to $0.88 ; 0.99$; $1.04 ; 1.08$ e $1.24 \%$, with the same relations between the remaining amino acids. The litters were standardized with 11 piglets. These animals were distributed in a completely randomized blocks experimental design, and each litter was considered an experimental unit, in a total of 10 repetitions. The results were evaluated through statistical variance models, using linear regression. It was concluded, that the different lysine levels did not influence the performance of piglets, and so, it is possible to use the lower studied level $(0.88 \%$ of digestible lysine) in the diet of primiparous sows in lactation.
\end{abstract}

Key Worde: digestible amino acids; embryos; primiparous lactation 


\section{INTRODUÇÃO}

As matrizes suínas disponíveis atualmente no mercado são mais precoces, mais produtivas, possuem maior peso corporal e são mais exigentes nutricionalmente. Outro fator a ser considerado é que fêmeas suínas de primeiro parto apresentam uma maior dificuldade durante a lactação, por apresentarem um consumo menor de ração, devido a sua menor capacidade gastrintestinal, não conseguindo atender a demanda de produção láctea e manter um bom desenvolvimento corporal (Paiva, 2004). O menor consumo de alimento pelas matrizes suínas aumenta a mobilização de tecido corporal, ocorrendo diminuição nos níveis de insulina e triiodotironina (T3) e aumentando os de cortisol. A diminuição dos níveis de insulina acarretará diminuição posterior nas quantidades de IGF-1 e $\mathrm{GnRH}$, cuja diminuição promoverá alterações nas quantidades de $\mathrm{FSH} / \mathrm{LH}$, culminando assim na diminuição do desenvolvimento folicular, reduzindo a ovulação e aumentando o intervalo desmame-cio (Hughes e Pierce, 1989).

O baixo consumo de lisina durante a lactação influencia o estado metabólico, a secreção de $\mathrm{LH}$ e o intervalo desmame-cio, além de aumentar a mobilização de proteína corporal (Yang et al., 2000b), sendo que tais alterações podem influenciar diretamente 0 peso dos leitões à desmama, bem como o desempenho da leitegada subseqüente.

Entre os aminoácidos mais importantes que compõem as dietas, a lisina é o mais estudado, principalmente pelo fato de ser o primeiro aminoácido limitante para suínos e utilizado como referência para a formulação de dietas (Cota et al., 2003). Deste modo, o conceito de proteína ideal tem sido utilizado para estimar as necessidades de aminoácidos, a partir do conhecimento da exigência de lisina, tomando-a como aminoácido referência (Nunes et al. 2006).

As primíparas que apresentam perda excessiva de peso durante a lactação podem vir a ter um maior intervalo entre partos, maiores chances de anestro, menores taxas de parição e de sobrevivência dos embriões e diminuição no peso da leitegada subseqüente (Aherne e Foxcroft, 2000). De acordo com o NRC (1998), matrizes suínas mantidas a $22^{\circ} \mathrm{C}$, com peso médio ao parto de $170,0 \mathrm{~kg}$, perdendo em média $6,0 \mathrm{~kg}$ durante a lactação e amamentando 11 leitões durante 21 dias, com um ganho médio diário de 210 gramas, apresentam exigência de lisina digestível de 0,92\% e/ou 37,9 g/dia.

Desta forma, o objetivo foi analisar se a ingestão diária de diferentes quantidades de lisina pelas fêmeas suínas primíparas em lactação, influencia 0 peso dos leitões ao desmame, o número de fetos e o peso dos leitões no segundo parto.

\section{MATERIAL E MÉTODOS}

O estudo foi conduzido em uma granja comercial, situada na região Oeste do Paraná, entre os meses de outubro de 2006 a abril de 2007. As temperaturas máxima e mínima no interior das instalações foram aferidas diariamente às $8 \mathrm{~h}$ e $17 \mathrm{~h}$. Utilizou-se inicialmente 50 fêmeas da linhagem C40 (Animais F1 de cruzamentos entre machos da raça Pietran e fêmeas da raça Large White) de primeiro parto.

Durante a gestação, todas as fêmeas receberam o mesmo manejo alimentar até o $107^{\circ} \mathrm{e} / \mathrm{ou} 110^{\circ}$ dia de gestação, distribuído da seguinte forma:

Ração de Gestação: 2,5 kg de ração por dia da cobertura até o $30^{\circ}$ dia 
Tabela 1 - Composição das dietas experimentais

\begin{tabular}{|c|c|c|c|c|c|}
\hline \multirow[b]{2}{*}{ Ingredientes (\%) } & \multicolumn{5}{|c|}{ Níveis de lisina digestível na ração (\%) } \\
\hline & 0,88 & 0,99 & 1,04 & 1,08 & 1,24 \\
\hline Milho & 61,49 & 61,30 & 61,12 & 61,12 & 60,94 \\
\hline Soja Integral Tostada & 19,50 & 18,70 & 18,00 & 17,20 & 16,40 \\
\hline Farelo de Soja 45\% & 9,10 & 9,80 & 10,50 & 11,10 & 11,80 \\
\hline Farelo de Trigo & 3,00 & 3,00 & 3,00 & 3,00 & 3,00 \\
\hline Óleo de Soja & 2,10 & 2,20 & 2,20 & 2,20 & 2,30 \\
\hline Fosfato Bicálcico & 2,40 & 2,40 & 2,40 & 2,40 & 2,40 \\
\hline Calcário Calcítico & 0,440 & 0,438 & 0,435 & 0,433 & 0,430 \\
\hline Sal Comum & 0,180 & 0,168 & 0,155 & 0,143 & 0,130 \\
\hline Bicarbonato de Sódio & 0,490 & 0,508 & 0,525 & 0,543 & 0,560 \\
\hline L-Lisina $\mathrm{HCl}$ & 0,260 & 0,323 & 0,385 & 0,448 & 0,510 \\
\hline L-Triptofano & 0,010 & 0,019 & 0,027 & 0,036 & 0,045 \\
\hline L-Treonina & 0,050 & 0,085 & 0,119 & 0,154 & 0,189 \\
\hline DL-Metionina & 0,020 & 0,048 & 0,075 & 0,103 & 0,130 \\
\hline L-Valina & 0,050 & 0,088 & 0,125 & 0,163 & 0,200 \\
\hline L-Isoleucina & 0,000 & 0,015 & 0,030 & 0,045 & 0,060 \\
\hline L-Histidina & 0,000 & 0,005 & 0,010 & 0,015 & 0,020 \\
\hline Sulfato de Cobre & 0,090 & 0,090 & 0,090 & 0,090 & 0,090 \\
\hline Sacarina Sódica & 0,016 & 0,016 & 0,016 & 0,016 & 0,016 \\
\hline Mistura Vitamínica ${ }^{1}$ & 0,40 & 0,40 & 0,40 & 0,40 & 0,40 \\
\hline Mistura Mineral $^{2}$ & 0,10 & 0,10 & 0,10 & 0,10 & 0,10 \\
\hline Antioxidante $^{3}$ & 0,01 & 0,01 & 0,01 & 0,01 & 0,01 \\
\hline Inerte & 0,29 & 0,29 & 0,28 & 0,28 & 0,27 \\
\hline Total & 100,0 & 100,0 & 100,0 & 100,0 & 100,0 \\
\hline \multicolumn{6}{|c|}{ 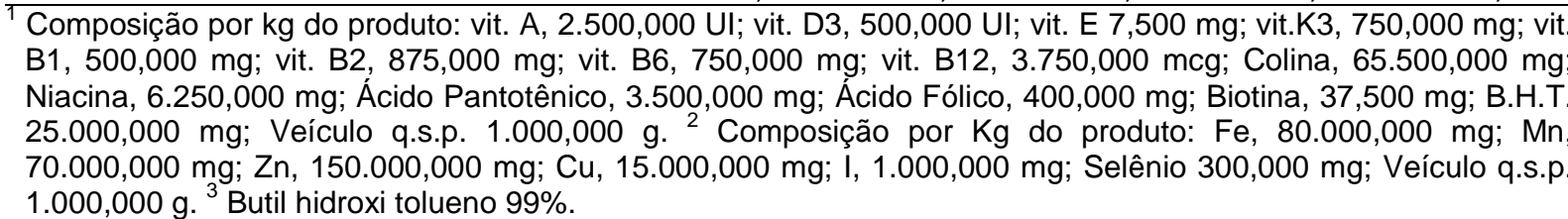 } \\
\hline
\end{tabular}

e 2,6 kg de ração por dia do $31^{\circ}$ ao $85^{\circ}$ dia de gestação. A dieta de gestação foi formulada para conter: $2.438 \mathrm{kcal} \mathrm{kg}^{-1}$ de energia digestível, $13,28 \%$ de proteína bruta, $0,87 \%$ de cálcio e $0,65 \%$ de fósforo total.

Ração de Pré-lactação: $3,0 \mathrm{~kg}$ de ração por dia do $86^{\circ}$ ao $107^{\circ} \mathrm{e} / \mathrm{ou} 110^{\circ}$ dia de gestação. Esta dieta foi formulada para conter: $2.554 \mathrm{kcal} \mathrm{kg}^{-1}$ de energia digestível, $14,0 \%$ de proteína bruta, $0,87 \%$ de cálcio e $0,62 \%$ de fósforo total. No período que antecedeu ao parto (em média cinco dias), os animais receberam $1,5 \mathrm{~kg}$ de ração lactação por dia; no primeiro parto, os animais receberam as diferentes dietas experimentais (Tabela 1 e 2 ). No segundo parto, todos os animais receberam dieta padrão, formulada para apresentar: $3.422 \mathrm{Kcal} \mathrm{kg}^{-1}$ de energia digestível, $17,41 \%$ de proteína bruta, $0,88 \%$ de cálcio e $0,65 \%$ de fósforo total, sendo está dieta fornecida em média cinco dias antes do parto até o momento do desmame.

Devido as dietas de gestação e prélactação possuírem a silagem de grão úmido de sorgo em suas fórmulas, realizou-se a determinação do diâmetro geométrico médio (DGM) das dietas para se especificar a sua granulometria. Elas apresentaram DGM médio de 611 micrômetros $(\mu \mathrm{m})$, valor dentro da amplitude de variação recomendada pela Embrapa (2007), que estipula um valor ideal entre 500 e 650 um para suínos.

Os tratamentos utilizados durante $o$ 
Tabela 2 - Composição nutricional das dietas experimentais

\begin{tabular}{|c|c|c|c|c|c|}
\hline \multirow[b]{2}{*}{ Composição analisada (\%) } & \multicolumn{5}{|c|}{ Níveis de lisina digestível na ração (\%) } \\
\hline & 0,88 & 0,99 & 1,04 & 1,08 & 1,24 \\
\hline Proteína Bruta $^{1}$ & 17,51 & 17,83 & 17,64 & 17,89 & 17,59 \\
\hline Fibra Bruta ${ }^{1}$ & 3,64 & 4,31 & 3,66 & 3,55 & 3,26 \\
\hline Cálcio ${ }^{1}$ & 1,00 & 0,93 & 0,90 & 0,88 & 0,93 \\
\hline Fósforo Total $^{1}$ & 0,83 & 0,76 & 0,72 & 0,72 & 0,77 \\
\hline Fósforo Disponível ${ }^{2}$ & 0,55 & 0,50 & 0,48 & 0,48 & 0,51 \\
\hline Lisina Total $^{1}$ & 1,01 & 1,13 & 1,18 & 1,21 & 1,39 \\
\hline Lisina Digestível $^{2}$ & 0,88 & 0,99 & 1,04 & 1,08 & 1,24 \\
\hline Metionina Total $^{1}$ & 0,28 & 0,33 & 0,36 & 0,35 & 0,43 \\
\hline Metionina Digestível $^{2}$ & 0,24 & 0,29 & 0,32 & 0,31 & 0,38 \\
\hline Metionina + Cistina Total ${ }^{1}$ & 0,56 & 0,63 & 0,67 & 0,6 & 0,72 \\
\hline Metionina + Cistina Digestível ${ }^{2}$ & 0,48 & 0,54 & 0,58 & 0,53 & 0,64 \\
\hline Treonina Total $^{1}$ & 0,70 & 0,79 & 0,84 & 0,78 & 0,92 \\
\hline Treonina Digestível $^{2}$ & 0,58 & 0,66 & 0,71 & 0,67 & 0,79 \\
\hline Arginina Total $^{1}$ & 1,12 & 1,21 & 1,24 & 1,09 & 1,21 \\
\hline Arginina Digestível $^{2}$ & 1,00 & 1,09 & 1,11 & 0,98 & 1,09 \\
\hline Leucina Total $^{1}$ & 1,52 & 1,65 & 1,65 & 1,62 & 1,78 \\
\hline Leucina Digestível $^{2}$ & 1,36 & 1,48 & 1,49 & 1,46 & 1,60 \\
\hline Isoleucina Total $^{1}$ & 0,78 & 0,78 & 0,81 & 0,74 & 0,82 \\
\hline Isoleucina Digestível $^{2}$ & 0,60 & 0,65 & 0,67 & 0,63 & 0,70 \\
\hline Valina Total $^{1}$ & 0,86 & 0,94 & 1,00 & 0,94 & 1,08 \\
\hline Valina Digestível $^{2}$ & 0,72 & 0,79 & 0,85 & 0,81 & 0,94 \\
\hline Histidina Total ${ }^{1}$ & 0,46 & 0,51 & 0,52 & 0,48 & 0,54 \\
\hline Histidina Digestível $^{2}$ & 0,40 & 0,44 & 0,45 & 0,42 & 0,47 \\
\hline Fenilalamina Total ${ }^{1}$ & 0,81 & 0,87 & 0,88 & 0,88 & 0,96 \\
\hline Fenilalamina Digestível $^{2}$ & 0,69 & 0,77 & 0,81 & 0,85 & 0,92 \\
\hline Energia Metabolizável $(\mathrm{kcal} / \mathrm{kg})^{3}$ & 3.330 & 3.330 & 3.330 & 3.330 & 3.330 \\
\hline
\end{tabular}

período experimental consideraram em diferentes quantidades de lisina digestível na dieta, correspondendo a 0,88; 0,99; 1,$04 ; 1,08$ e $1,24 \%$, mantendo-se sempre a relação ideal entre os demais aminoácidos. Todos os animais receberam uma dieta formulada com base nas exigências nutricionais estabelecidas por Rostagno et al. (2005) para a fase de lactação.

Aos 107 e/ou 110 dias de gestação, os animais foram levados para a sala de maternidade, onde ficaram alojados individualmente em gaiolas convencionais, providas de comedouro, bebedouro e sistema de aquecimento para os leitões.
Os animais iniciaram o consumo das dietas em média cinco dias antes do parto, para a adaptação às dietas experimentais. Essas rações foram fornecidas umedecidas, em quantidade inicial de $3,19 \mathrm{~kg}$ de ração por dia (correspondente ao período de adaptação até os 10 primeiros dias de lactação). E, posteriormente, foram fornecidos $7,5 \mathrm{~kg}$ de ração por dia (11ํㅜㅇ ao $21^{\circ}$ dia de lactação), sendo as rações fornecidas em duas refeições diárias. $\mathrm{O}$ acesso à água foi à vontade.

Após o período de lactação, as matrizes foram conduzidas para as instalações de gestação, onde receberam ração de lactação à vontade 
até a cobertura, quando foi iniciado manejo nutricional para o período de gestação. Antes de cada novo arraçoamento, as sobras de rações da refeição anterior foram coletadas e levadas imediatamente ao laboratório aonde foram secas em estufa a $55^{\circ} \mathrm{C}$, por um período de 96h, para determinação do consumo de ração de lactação.

Amostras das dietas de lactação e gestação foram analisadas no laboratório de nutrição animal da Universidade Federal do Paraná, conforme as técnicas descritas por Silva (1990), para proteína bruta, extrato etéreo, energia bruta, fibra bruta, cálcio e fósforo. As análises químicas para determinar as quantidades de aminoácidos presentes na dieta de lactação foram realizadas pela Ajinomoto Biolatina Ind. e Com. Ltda, utilizando-se a cromatografia líquida de alta performance (HPLC), conforme descrito na AOAC Official Method 994.12 (1995).

As fêmeas suínas primíparas utilizadas neste estudo foram uniformizadas conforme 0 peso e a idade. Já as leitegadas foram padronizadas com 11 leitões cada até $24 \mathrm{~h}$ após o parto. Além da pesagem inicial, os leitões foram novamente pesados aos 21 dias (ao desmame). No segundo parto avaliou-se o número total de leitões nascidos (considerado os leitões nascidos vivos, natimortos e mumificados) e o peso dos leitões ao nascimento. Para determinação do peso dos leitões nascidos no segundo parto, foram pesados apenas os leitões nascidos vivos.

O delineamento experimental utilizado foi de blocos ao acaso (DBA), sendo o bloco considerado os diferentes períodos (semanas). Neste estudo, cada leitegada constituiu uma unidade experimental. Foram obtidas, assim, dez repetições, e cada bloco possuiu os diferentes tratamentos $(0,88 ; 0,99 ; 1,04$;
1,08 e 1,24\% de lisina digestível).

Os resultados foram avaliados pelos modelos estatísticos de análise de variância, por meio do procedimento GLM (General Linear Models), utilizando-se a regressão linear ou quadrática, conforme o melhor ajuste.

\section{RESULTADOS E DISCUSSÃO}

O consumo de alimento durante o estudo foi inferior ao esperado, pois, segundo o padrão genético desses animais, o consumo médio diário de alimento deveria ser de $3,19 \mathrm{~kg}$ de ração por dia do início da adaptação até o $10^{\circ}$ dia de lactação e de $7,5 \mathrm{~kg}$ por dia do $11^{\circ}$ ao $21^{\circ}$ dia de lactação. Entretanto, o consumo médio diário manteve-se em 3,08 kg e 4,53 kg, respectivamente para estes dois períodos. Assim, os animais apresentaram consumo 3,45\% menor até $010^{\circ}$ dia e $39,53 \%$ inferior ao esperado, do $11^{\circ}$ ao $21^{\circ}$ dia de lactação.

As temperaturas médias observadas nos termômetros foram $22,7 \pm 2,44^{\circ}$.C de média mínima às 8 h00 e $24,8 \pm 3,38^{\circ} \mathrm{C}$ às $17 \mathrm{~h} 00$. Para as temperaturas máximas foram registrados valores médios de $29,2 \pm 3,5^{\circ} \mathrm{C}$ e $29,2 \pm 3,57^{\circ} \mathrm{C}$, às $8 \mathrm{h00}$ e $17 \mathrm{~h} 00$, respectivamente. Segundo Black et al. (1993), a zona de conforto térmico na maternidade varia entre 12 e $2^{\circ} \mathrm{C}$ para fêmeas, sendo que, reduções drásticas em $40 \%$ na produção de leite e $25 \%$ no consumo de alimento podem ser observados em matrizes submetidas a estresse térmico $\left(28^{\circ} \mathrm{C}\right)$ em relação àquelas que são mantidas na zona de conforto térmico $\left(18^{\circ} \mathrm{C}\right)$. Diante destes resultados, é possível inferir que a temperatura ambiental tenha sido uma das principais causas do baixo consumo observado em relação ao consumo esperado.

Os resultados observados para as variáveis dos leitões ao nascimento em 
Tabela 3 - Desempenho dos leitões no momento do parto (primeira parição), com base nos dias em que as porcas receberam dietas experimentais antes do parto.

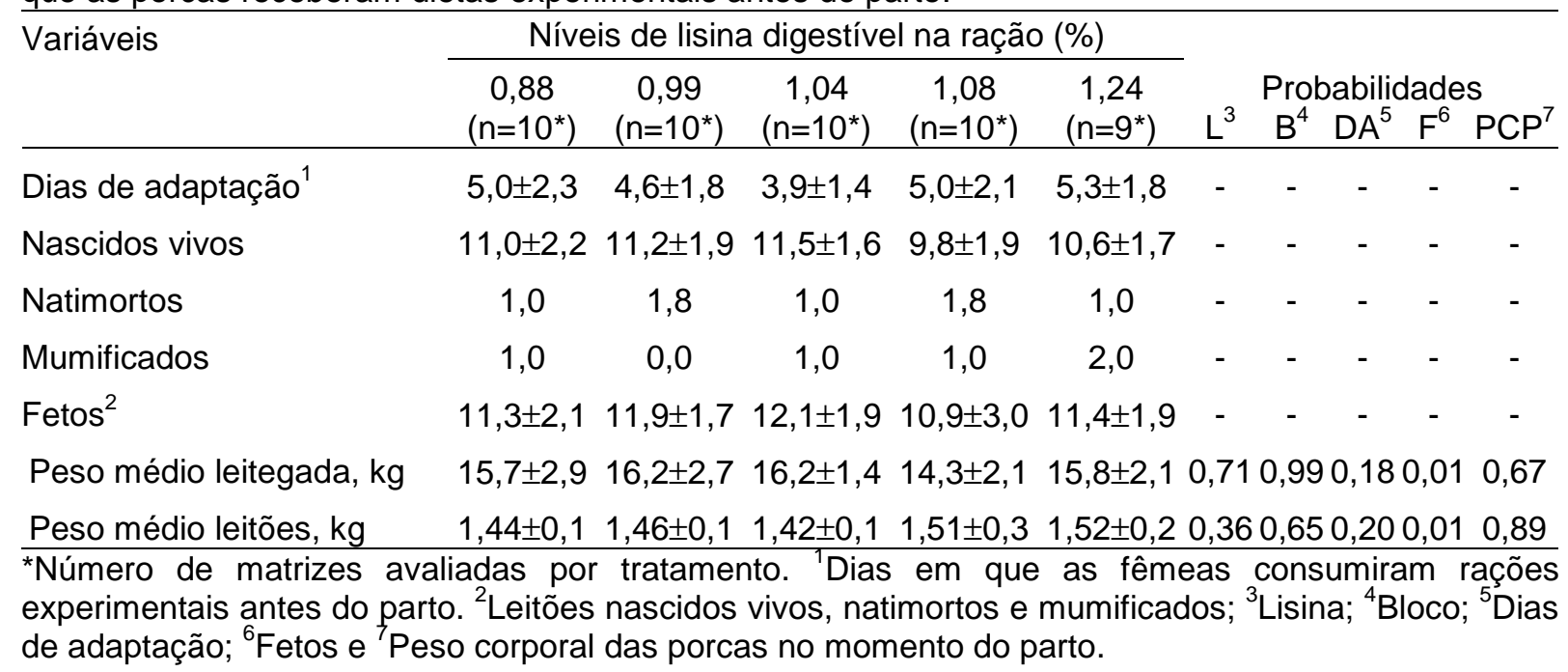

Tabela 4 - Desempenho da leitegada do nascimento ao desmame no primeiro parto

\begin{tabular}{|c|c|c|c|c|c|c|c|c|}
\hline \multirow[t]{3}{*}{ Variáveis } & \multicolumn{5}{|c|}{ Níveis de lisina digestível na ração (\%) } & \multirow{2}{*}{\multicolumn{3}{|c|}{ Probabilidades }} \\
\hline & \multirow{2}{*}{$\begin{array}{c}0,88 \\
\left(n^{*}=10\right)\end{array}$} & \multirow{2}{*}{$\begin{array}{c}0,99 \\
\left(n^{*}=10\right)\end{array}$} & \multirow{2}{*}{$\begin{array}{c}1,04 \\
\left(n^{*}=10\right) \\
\end{array}$} & \multirow{2}{*}{$\begin{array}{c}1,08 \\
\left(n^{*}=8\right)\end{array}$} & \multirow{2}{*}{$\begin{array}{c}1,24 \\
\left(n^{*}=9\right)\end{array}$} & & & \\
\hline & & & & & & Lisina & Bloco & $\mathrm{Pl}^{1}$ \\
\hline № de leitões & 110 & 110 & 110 & 88 & 99 & - & - & - \\
\hline № de leitões à desmama & 107 & 101 & 106 & 85 & 94 & - & - & - \\
\hline Média de leitões/matriz & 10,7 & 10,1 & 10,6 & 10,6 & 10,4 & - & - & - \\
\hline Mortalidade (\%) & 2,73 & 8,18 & 3,64 & 3,41 & 5,05 & - & - & - \\
\hline \multicolumn{9}{|l|}{ Peso médio dos Leitões, kg } \\
\hline Ao nascer & $1,51 \pm 0,097$ & $1,58 \pm 0,199$ & $1,53 \pm 0,159$ & $1,54 \pm 0,230$ & $1,56 \pm 0,185$ & - & - & - \\
\hline Ao Desmame & $5,97 \pm 0,405$ & $6,11 \pm 0,443$ & $5,89 \pm 0,638$ & $5,82 \pm 0,708$ & $6,00 \pm 0,606$ & 0,67 & 0,23 & 0,01 \\
\hline Ganho em peso & $4,45 \pm 0,360$ & $4,52 \pm 0,379$ & $4,36 \pm 0,613$ & $4,28 \pm 0,614$ & $4,44 \pm 0,542$ & 0,67 & 0,23 & 0,16 \\
\hline Ganho médio em peso & $0,21 \pm 0,017$ & $0,22 \pm 0,018$ & $0,21 \pm 0,029$ & $0,20 \pm 0,029$ & $0,21 \pm 0,026$ & 0,67 & 0,23 & 0,16 \\
\hline \multicolumn{9}{|c|}{ Peso médio da leitegada, $\mathrm{kg}$} \\
\hline Ao nascer ${ }^{1}$ & $16,65 \pm 1,06$ & $17,41 \pm 2,20$ & $16,80 \pm 1,75$ & $16,95 \pm 2,51$ & $17,18 \pm 2,03$ & - & - & - \\
\hline Ao Desmame & $65,65 \pm 4,47$ & $67,21 \pm 4,88$ & $64,79 \pm 7,01$ & $64,07 \pm 7,79$ & $65,99 \pm 6,66$ & 0,65 & 0,22 & 0,01 \\
\hline Ganho em peso & $49,00 \pm 3,98$ & $49,80 \pm 4,19$ & $47,98 \pm 6,73$ & $47,12 \pm 6,75$ & $48,81 \pm 5,95$ & 0,65 & 0,22 & 0,16 \\
\hline Ganho médio em peso & $2,33 \pm 0,19$ & $2,37 \pm 0,20$ & $2,28 \pm 0,32$ & $2,24 \pm 0,32$ & $2,32 \pm 0,28$ & 0,65 & 0,22 & 0,16 \\
\hline
\end{tabular}

função do período de adaptação das porcas, bem como durante o período de amamentação após a padronização das leitegadas, estão expostos nas tabelas 3 e 4, respectivamente.

O ganho em peso dos leitões ao nascimento (Tabela 3) não foi influenciado $(P>0,05)$ pelos tratamentos fornecidos antes do parto, sendo que este resultado pode ser explicado visto que essas matrizes receberam quantidade baixa de ração $(1,5 \mathrm{~kg})$, como parte de um manejo preparatório para o parto.

Não houve diferença significativa $(P>0,05)$ no ganho de peso médio diário e ganho de peso total dos leitões e das leitegadas (Tabela 4), apesar do consu- 
Tabela 5 - Número de fetos e peso médio dos leitões ao nascimento no segundo parto

\begin{tabular}{|c|c|c|c|c|c|c|c|c|}
\hline \multirow[t]{3}{*}{ Variáveis } & \multicolumn{5}{|c|}{ Níveis de lisina digestível na ração (\%) } & \multirow{2}{*}{\multicolumn{3}{|c|}{ Probabilidades }} \\
\hline & 0,88 & 0,99 & 1,04 & 1,08 & 1,24 & & & \\
\hline & $\left(n=10^{*}\right)$ & $\left(n=9^{\star}\right)$ & $\left(n=7^{\star}\right)$ & $\left(n=8^{\star}\right)$ & $\left(\mathrm{n}=8^{*}\right)$ & Lisina & Bloco & PCPD $^{1}$ \\
\hline Nascidos vivos & $11,70 \pm 3,6$ & $10,67 \pm 5,1$ & $13,43 \pm 2,0$ & $10,88 \pm 4,5$ & $10,88 \pm 3,8$ & - & - & - \\
\hline Natimortos & 1,7 & 3,4 & 1,5 & 5 & 3,6 & - & - & - \\
\hline Mumificados & 2,6 & 4,0 & 0,0 & 1,0 & 1,5 & - & - & - \\
\hline $\begin{array}{l}\text { Fetos }^{1} \\
\text { Peso médio das }\end{array}$ & $14,0 \pm 2,0$ & $13,9 \pm 2,5$ & $13,9 \pm 2,5$ & $13,3 \pm 2,3$ & $13,9 \pm 1,6$ & 0,73 & 0,42 & 0,63 \\
\hline $\begin{array}{l}\text { leitegadas, } \mathrm{kg} \\
\text { Peso médio dos }\end{array}$ & $16,58 \pm 5,6$ & $14,78 \pm 7,6$ & $19,01 \pm 2,2$ & $15,63 \pm 6,4$ & $14,86 \pm 5,1$ & 0,73 & 0,98 & 0,88 \\
\hline Leitões, kg & $1,40 \pm 0,25$ & $1,35 \pm 0,18$ & $1,43 \pm 0,14$ & $1,42 \pm 0,27$ & $1,40 \pm 0,18$ & 0,95 & 0,94 & 0,52 \\
\hline
\end{tabular}

mo de lisina digestível pelas matrizes variar entre 36,21 e 52,21 g/dia. De forma semelhante, Cota et al. (2003) e Paiva et al. (2005), trabalhando com níveis entre 35,3 a $47,3 \mathrm{~g}$ de lisina digestível por dia, e Touchette et al. (1998), avaliando níveis entre 27,0 e 43,0 $\mathrm{g}$ de lisina digestível por dia, não verificaram efeito na variação de peso dos leitões e/ou leitegadas durante a lactação. Nunes et al. (2006), fornecendo rações contendo níveis de lisina entre 39,2 a 53,0 g de lisina digestível por dia para fêmeas de segundo parto em diante, não observaram diferenças no peso dos leitões ao desmame.

Entretanto, Yang et al. (2000a) avaliando o consumo de 16,0; 36,0; e $56,0 \mathrm{~g}$ de lisina digestível por dia em matrizes suínas primíparas em lactação, observaram menor ganho de peso da leitegada das porcas que receberam o menor nível de lisina, sendo que tais resultados podem ser explicados devido ao baixo consumo diário de lisina $(16,0$ $\mathrm{g}$ ), pelas fêmeas, no tratamento de menor nível.

O desempenho dos leitões pode ter sido influenciado pelo baixo consumo de alimento pelas fêmeas, visto que apresentaram um consumo $3,45 \%$ menor nos primeiros 10 dias e de $39,53 \%$ do $11^{\circ}$ ao $21^{\circ}$ dia lactação, levando-se em conta o consumo espe- rado para esses animais. Esse baixo consumo pode ser devido às altas temperaturas, bem como à menor capacidade gastrintestinal para consumo de alimento que as fêmeas de primeiro parto apresentam quando comparadas a fêmeas de demais partos.

Como observado na tabela 5 , os resultados para 0 peso médio dos leitões ao nascimento e número de fetos no segundo parto não foram influenciados $(P>0,05)$ pelos tratamentos. Paiva et al. (2005) não observaram efeito $(P>0,05)$ do consumo de lisina sobre o número de leitões nascidos no segundo parto. Porém, as fêmeas que consumiram 47,3 $\mathrm{g}$ de lisina digestível por dia durante a lactação, apresentaram aumento de 1,2 leitões no segundo parto, quando comparadas aos animais que consumiram $35,3 \mathrm{~g}$ de lisina digestível por dia. Salienta-se que o coeficiente de variação para o número leitões nascidos vivos foi igual a 21,2\%.

De modo semelhante, Bianchi et al. (2006) trabalhando com fêmeas de primeiro e segundo partos, consumindo dois níveis de lisina total $(39,9$ e $64,6 \mathrm{~g}$ por dia) e/ou digestível (35,5 e 57,5 g por dia, considerando uma digestibilidade média de $89 \%$ ), não observaram diferenças para o total de leitões nascidos no parto posterior. 


\section{CONCLUSÃO}

Conclui-se que os diferentes níveis de lisina nas rações das progenitoras não influenciaram o desempenho dos leitões, bem como o peso e número de fetos no segundo parto, podendo assim, ser utilizado o menor nível estudado (0,88\% de lisina digestível) na dieta de porcas primíparas em lactação.

\section{AGRADECIMENTO}

A granja Becker. A Ajinomoto Biolatina Ind. e Com. Ltda ao CNPq pela bolsa concedida.

\section{NOTA INFORMATIVA}

Aprovação na comissão de ética no uso de animais, em 23 de agosto de 2006 (protocolo no 037/2006) na Universidade Federal do Paraná, Centro de Ciências Agrárias.

\section{REFERÊNCIAS}

AHERNE, F.; FOXCROFT,G. Manejo da leitoa e da porca primípara: parte $\mathrm{V}$. manejo nutricional na gestação e lactação. In: SIMPÓSIO INTERNACIONAL DE REPRODUÇÃO E INSEMINAÇÃO ARTIFICIAL EM SUÍNOS, 7., 2000, Foz do Iguaçu, PR. Anais... Foz do Iguaçu. 2000. p.145-165.

AOAC - Association of official analytical chemist. In: Official methods of analysis of the association of official analytical chemists. 16 th ed, v.2, chapter 45, 1995, Washington, DC, 1995.

BIANCHI, I.; DESCHAMPS, J.C.; THOMAZ JR. L. et al. Desempenho de fêmeas suínos de primeiro e segundo partos em função do fornecimento de diferentes níveis de lisina na dieta de lactação. Revista Brasileira

Agrociência, v.12, n.3, p.345-349, 2006.

BLACK, J.L.; MULLAN, B.P.; LORSCHY, M.L. et al. Lactation in the sow during heat stress.

Livestock production science, v.35, p.153170, 1993.

COTA, T.S.; DONZELE, J.L.; OLIVEIRA.; F.M. et al. Níveis de lisina em ração de lactação para fêmeas suínas primíparas. Revista Brasileira de Zootecnia, v.32, n.1, p.115-122, 2003.

Empresa Brasileira de Pesquisa Agropecuária EMBRAPA. Tamanho da partícula do milho na alimentação de suínos e aves poderá o comprometer desempenho animal e os custos de produção da ração. Disponível em: http://www.cnpsa.embrapa.br/?ids=\&idn=27. Acesso em: 20/07/2007.

HUGHES, P.E.; PEARCE, G.P. In: MANIPULATING PIG PRODUCTION, II. 1989, Australian, Proceedings... Bernett,J.L., Hennessy, D.P. (eds) Australian Pig Science Association, 1989. p.290-295.

NATIONAL RESEARCH COUNCIL - NRC. Nutrient requirements of swine. 10.ed. Washington, D.C.: National Academic Science, Committee Animal Nutrition. Subcommittee of Swine Nutrition, 1998. 189p.

NUNES, C.G.V.; OLIVEIRA, R.F.M.; DONZELE, J.L. et al. Níveis de lisina em rações para fêmeas suínas em lactação. Revista Brasileira de Zootecnia, v.35, p.1744-1751, 2006.

PAIVA, F.P. Lisina e energia digestível em rações para fêmeas suínas primíparas em lactação. Viçosa, MG: UFV, 2004. Tese (Doutorado em Zootecnia) - Universidade Federal de Viçosa.

PAIVA, T.S.; DONZELE, J.L.; OLIVEIRA, R.F.M. et al. Níveis de lisina em ração de lactação para fêmeas suínas primíparas. Revista Brasileira de Zootecnia, v.34, n.6, p.1917-1979, 2005.

ROSTAGNO, H.S.; ALBINO, L.F.T.; DONZELE, J.L. et al. Tabelas brasileiras para aves e suínos: composição de alimentos e exigências nutricionais. 2.ed. Viçosa, MG: Universidade Federal de Viçosa, 2005. 189p.

SILVA, D.J. Análise de alimentos (Métodos químicos e biológicos). 2.ed. Viçosa: Universidade Federal de Viçosa, 1990. 165 p.

TOUCHETTE, K.J.; ALLEE, G.L.; NEWCOMB, M.D. et al.. The lysine requirement of lactating primiparous sows. Journal of Animal Science, v.76, p.1091-1097, 1998.

YANG, H.; PETTIGREW, J.E.; JOHNSTON, L.J. et al. Lactational and subsequent reproductive responses of lactating sows to dietary lysine (protein) concentration. Journal of Animal Science, v.78, p.348-357, 2000a.

YANG, H.; PETTIGREW, J.E.; JOHNSTON, L.J. et al. Effects of dietary lysine intake during lactation on blood metabolites, hormones, and reproductive performance in primiparous sows. Journal of Animal Science. v.78, p.1001-1009, $2000 \mathrm{~b}$ 